\title{
ECONOMIC POLICY OF SUSTAINABLE DEVELOPMENT BASED ON IS-LM-EE MODEL
}

\author{
ZHANG, M. R. ${ }^{1,2}-$ LEE, C. M. ${ }^{2 *}$ \\ ${ }^{1}$ School of Economics, Yangtze University, Jingzhou, 434020, China \\ ${ }^{2}$ Institute of Natural Resources Management, National Taipei University, New Taipei City, \\ 23741,Taiwan \\ *Corresponding author \\ cmlee@mail.nptu.edu.tw \\ (Received 20 $0^{\text {th }}$ Dec 2016; accepted $7^{\text {th }}$ Mar 2017)
}

\begin{abstract}
Economic development is closely related to environmental quality. Environmental quality has become an important influencing factor to restrict the economic development. But environment quality is facing an ordeal owing to the pollution of the soil and water, greenhouse gas, extreme climate and natural disasters. It is one of the research focuses of scholars how to realize a harmonious development of economic and environmental by using fiscal and monetary policy tools. We revise the IS-LM-EE schedule model in the existing literature and discuss the stability conditions and the policy signification of the equilibrium point of the IS-LM-EE schedule model. We research the optimal fiscal and money policy combination at the equilibrium point of the IS-LM-EE model.
\end{abstract}

Keywords: environmental macroeconomics, sustainable development, IS-LM-EE model

\section{Introduction}

Economic development is closely related to environmental quality, the environment provides energy and raw materials for economic development, and the economic development discards a large amount of the waste in natural environment and changes the environment quality. The theories of the Classical Political Economic thought that the carrying capacity of the environment is the ultimate limiting factor of an economy's scale (Rezai and Stagl, 2016). How to realize a harmonious development of economic and environmental by using fiscal and monetary policy tools is one of the focuses of scholars' research. Daly (1991) studied the macroeconomic problems with the limited environmental resources and constructed the theory system of environmental macroeconomics. Heyes (2000) firstly set up the IS-LM-EE schedule model to research the economic policy collocation form of sustainable development. Lawn (2003), Sim (2006), Decker and Wohar (2012) also built different the IS-LM-EE schedule model to analyze the economic policy implication of the model. Heyes (2000) and Sim (2006) assumed the substitution of the environmental capital for physical capital and the EE schedule with the negative slope was steeper than the IS schedule. Therefore, the tight fiscal and expansionary monetary policy will be adopted in order to promote economic growth and maintain the equilibrium of environmental schedule. But Lawn (2003), Decker and Wohar (2012) denied the hypothesis of the substitution of the environmental capital for the physical capital, they argued the complementariness of the environmental capital for physical capital and the EE schedule with the positive slope was steeper than the LM schedule. They claimed the tight monetary and expansionary fiscal policy would be adopted in order to promote economic growth and maintain the equilibrium of environmental schedule. Fontana and Sawyer (2016), Jackson and Victor 
(2016), Rezai et al. (2013), and Taylor et al. (2016) also researched the major role of the standard macroeconomic policy tools in promoting the sustainable economic growth . The fiscal spending could complement the efforts to improve environmental quality, rendering environmental policy easier and more cost efficient (Halkos and Paizanos, 2015), Bowen et al. (2014). Campiglio (2014), Jackson and Victor (2015), Naqvi (2015) analyzed the importance of the policies for financial markets with the environmental sustainability. Bernardo and Campiglio (2014), Daly (2013, 2014), Douthwaite (2012), Seyfang and Longhurst (2013), had been studying the financial system for the sustainable economic growth .

The IS-LM-EE model does not analyze the stability condition of the equilibrium point in the existing literature. In addition, Decker and Wohar (2012) postulated that environmental and physical capital had a linear relationship, so the environmental schedule EE will be a hyperbolic curve rather than a straight line, the IS and LM schedule will have one or two points of intersection with EE schedule. The stability condition and the policy signification are different with the equilibrium point for the different slope of the EE schedule. Therefore, the paper will discuss the policy signification of the stability condition in the different IS-LM-EE model according to the assumption of the linear relationship of the environmental for the physical capital for Decker's and Wohar's (2012).

\section{Policy implications of the IS-LM-EE model}

\section{Constructjng IS-LM-EE Schedule Model}

In goods market, aggregate demand consistes of consumer demand, investment demand, government demand and net foreign demand. We assume that the investment demand function is: $I=I_{0}-b r$, where $I_{0}$ is autonomous investment spending and $b$

$(b>0)$ measures the sensitivity of investment to the interest rate, $r$. The consumption demand function is: $C=C_{0}+c Y_{d}$, where $C_{0}$ is an autonomous consumption and $c$ is the marginal propensity to consume with after-tax income, $Y_{d}=(1-t) Y$, where $t(0<t<1)$ is the tax rate and $Y$ is the aggregate output. The net foreign demand is $N X$ and the government demand is $G$. The aggregate demand function is : $A=C+I+N X+G$. Assumed the adjustments in the excess aggregate output can be written as $\frac{d Y}{d t}=\alpha(A-Y)$, where $\alpha(\alpha>0)$ is the adjustment coefficient of the aggregate demand. The product market reaches equilibrium when $\frac{d Y}{d t}=0$. So the IS schedule is as follows:

$$
r=-\frac{1-c(1-t)}{b} Y+\frac{C_{0}+I_{0}+N X+G}{b}
$$

So the slope of IS schedule is $k_{I S}=-\frac{1-c(1-t)}{b}<0$. The change of government purchase expenditures $G$ will cause the IS curve to shift when $C_{0}+I_{0}+N X$ is 
unchanged. So the behavior of the government purchase expenditures will determine the location of the IS schedule.

In the money market, we assume that the real money supply is $\frac{M_{0}}{P}$ and real money demand is $g Y-h r$, where $M_{0}$ is the nominal money supply and the price level $P$ is exogenous, $g(g>0)$ is the sensitivity coefficient of money demand to total output and $h(h>0)$ is the sensitivity coefficient of money demand to changes in the interest rate. The adjustments in the excess money demand can be written as $\frac{d r}{d t}=\beta\left(g Y-h r-\frac{M_{0}}{P}\right)$, where $\beta(\beta>0)$ is the adjustment coefficient of the excess money demand. The money market achieves equilibrium when $\frac{d r}{d t}=0$. Therefore, the LM curve is as follows:

$$
r=\frac{g}{h} Y-\frac{M_{0}}{P h}
$$

So the slope of LM schedule is $k_{L M}=\frac{g}{h}>0$ and $\frac{M_{0}}{P}$ determine the location of the LM schedule.

In environmental capital market, we assume the consumption function of environmental capital is: $e(r) Y=\left(e_{0}+\delta r\right) Y$, where, $e(r)$ is the consumption intensity of the environmental capital and $e(r)=e_{0}+\delta r$, where $e_{0}$ is the environmental capital consumption intensity with given technology, $\delta$ is the coefficient of the environmental capital consumption intensity to the real interest rate $r$. It means the substitution(complementariness) of the environmental capital for the physical capital when $\delta>(<) 0$. We assume that the replication growth rate of environmental capital is $s E$ per unit time, where $s$ is the percent growth in the environmental stock and $E$ is the total fixed stock of environmental capital available to an economy that can be tapped as an energy input in production (Decker and Wohar, 2012). So the net rate of environmental resource stock growth is $-\frac{d E}{d t}=\left(e_{0}+\delta r\right) Y-s E$. The environmental equilibrium schedule EE is obtained when $\frac{d E}{d t}=0$. Therefore, the EE curve is as follows:

$$
r=\frac{s E}{\delta Y}-\frac{e_{0}}{\delta}
$$

So, the slope of EE schedule is $k_{E E}=-\frac{s E}{\delta Y^{2}}$.

Therefore,the Eq.1, Eq.2 and Eq.3 consist of IS-LM-EE model: 


$$
\left\{\begin{array}{c}
r=-\frac{1-c(1-t)}{b} Y+\frac{C_{0}+I_{0}+N X+G}{b} \\
r=\frac{g}{h} Y-\frac{M_{0}}{P h} \\
r=\frac{s E_{0}}{\delta Y}-\frac{e_{0}}{\delta}
\end{array}\right.
$$

The stability condition of the IS-LM-EE model requires $0>k_{E E}>k_{I S}$ when $\delta>0$, or, $k_{E E}>k_{L M}>0>k_{I S}$ when $\delta<0$ (proof see appendix).

The stability condition of $0>k_{E E}>k_{I S}$ means that the IS curve is steeper than the EE curve when environmental capital and physical capital are substitutes in production. In Heyes'(2000) IS-LM-EE model, he postulated that the EE curve is steeper than the IS curve, therefore, the equilibrium point is unstable in his IS-LM-EE model. The stability condition of $k_{E E}>k_{L M}>0>k_{I S}$ means that the EE curve is steeper than the LM curve when environmental capital and physical capital are complements in production. In Decker's and Wohar's (2012) IS-LM-EE model, he postulated that the EE curve is steeper than the LM curve, so, the equilibrium point is stable in their IS-LM-EE model.

\section{Policy implications of the stability condition of the IS-LM-EE model}

The slope of EE schedule is $k_{E E}=-\frac{s E}{\delta Y^{2}}>0$ when $\delta<0$. According to our hypothesis, EE schedule is hyperbola. Therefore, LM and EE schedule will have one or two points of intersection. As shown in Fig. 1, point A is a point of tangency of LM and EE schedule. The EE curve is steeper than the LM curve at point $C$ and LM curve is steeper than the EE curve at point B. According to the stability condition of the IS-LM$\mathrm{EE}$ model, the point $\mathrm{C}$ is a stable equilibrium point, but the point $\mathrm{B}$ is an unstable equilibrium point. So we only discuss the policy signification of the point $\mathrm{C}$. At point $\mathrm{C}$, the tight fiscal and expansionary monetary policy will be adopted if the government hopes to decrease the economic growth with the given $\mathrm{EE}$ schedule. The result is consistent with the conclusion of Decker' and Wohar' (2012) IS-LM-EE schedule model. the expansionary fiscal and tight monetary policy will be adopted if the government hopes to promote the economic growth with the given EE schedule. Upper limit of the expansionary fiscal and lower limit of tight monetary policy are the economic growth achieving the total output of point A. Therefore, there is the maxmium of the output with the environmental constraint, the the maxmium of the government expenditure , and the minimium of the real money supply at the point A. 


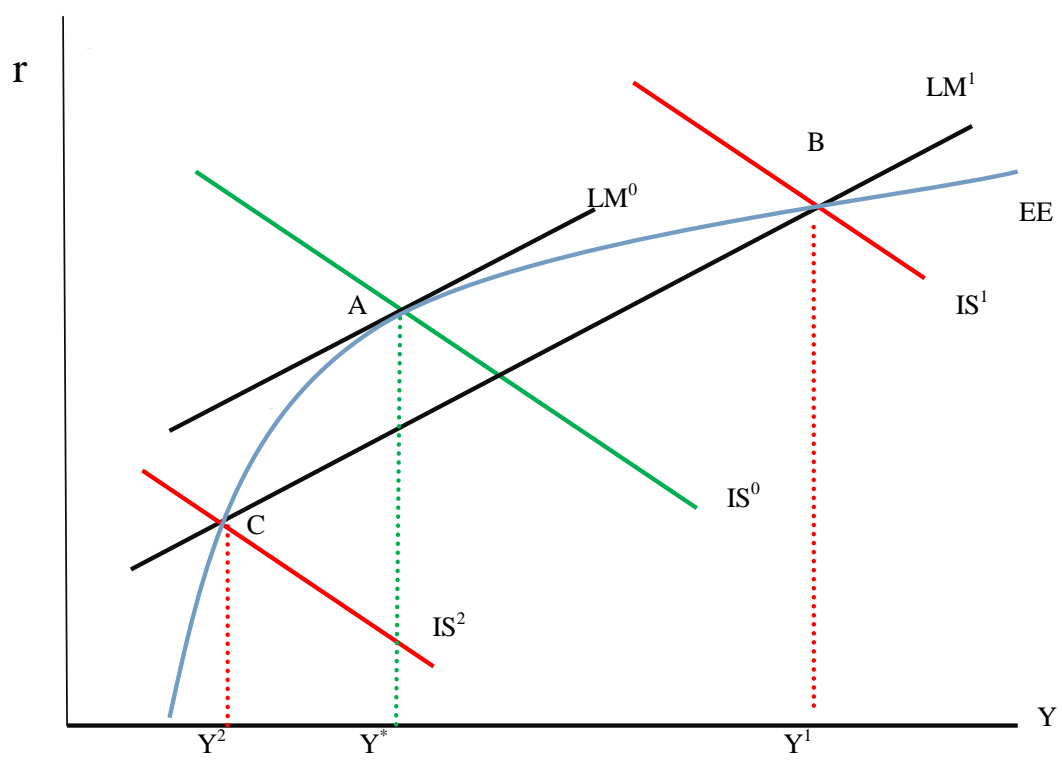

Figure 1. Policy implications in IS-LM-EE Model with EE Schedule of Positive Slope

Then, we discuss the minimium of the real money supply and maxmium of government expenditure at point A. The minimization problem of money supply is:

$$
\begin{array}{r}
\min \frac{M_{0}}{P}=\min _{(Y, r)}(g Y-h r) \\
\text { s.t } \quad\left(e_{0}+\delta r\right) Y=s E
\end{array}
$$

So, we will get the solution:

$$
\begin{gathered}
Y^{*}=\left(-\frac{h s E}{\delta g}\right)^{\frac{1}{2}} \\
r^{*}=-\frac{e_{0}}{\delta}-\left(-\frac{s g E}{h \delta}\right)^{\frac{1}{2}} \\
\left(\frac{M_{0}}{P}\right)^{\min }=2\left(-\frac{h s g E}{\delta}\right)^{\frac{1}{2}}+\frac{h e_{0}}{\delta}
\end{gathered}
$$

Eq.7 shows the maxmium of the output with the environmental constraint, Eq.9 shows the minimium of the real money supply in order to achieve the equilibrium of $\mathrm{EE}$ and LM. If the government hope to adjust the government purchase expenditure achieving the equilibrium of EE, IS and LM. So the maxmium of the government expenditure will be determined by Eq.1 , Eq.7 and Eq.8, then: 


$$
G^{\max }=[1-c(1-t)]\left(-\frac{h s E}{\delta g}\right)^{\frac{1}{2}}-b\left(-\frac{s g E}{h \delta}\right)^{\frac{1}{2}}-\frac{b e_{0}}{\delta}-\left(C_{0}+I_{0}+N X\right)
$$

Which equilibrium point does the government preference between $\mathrm{A}$ and $\mathrm{C}$ ? We think that the government will prefer equilibrium point $\mathrm{A}$ rather than $\mathrm{C}$. Because the total output of point $\mathrm{A}$ is higher than point $\mathrm{C}$, when the level of economic development is at the point $\mathrm{C}$, the government will adopt the expansionary fiscal and tight monetary policy to move the equilibrium point from $\mathrm{C}$ to $\mathrm{A}$.

The slope of EE schedule is $k_{E E}=-\frac{s E}{\delta Y^{2}}<0$ when $\delta>0$. According to our hypothesis, EE schedule is hyperbola and IS and EE schedule will have one or two points of intersection. As shown in Fig. 2, point A is a point of tangency of IS and EE schedule. The EE curve is steeper than the IS curve at point $\mathrm{C}$ and IS curve is steeper than the EE curve at point B. According to the stability condition of the IS-LM-EE model,so the point $\mathrm{C}$ is an unstable equilibrium point, but the point $\mathrm{B}$ is a stable equilibrium point. So we only discuss the policy signification of the point B. At point B, the expansionary fiscal and expansionary monetary policy will be adopted if the government hopes to promote the economic growth with the given EE schedule of negative slope. But Heyes (2000) and Sim (2006) thought that the tight fiscal and expansionary monetary policy would promote the economic growth with the given EE schedule of negative slope. According to the stability condition of the IS-LM-EE model, there are the minimium of the output, of the government expenditure and of the real money supply with the environmental constraint at the point A.

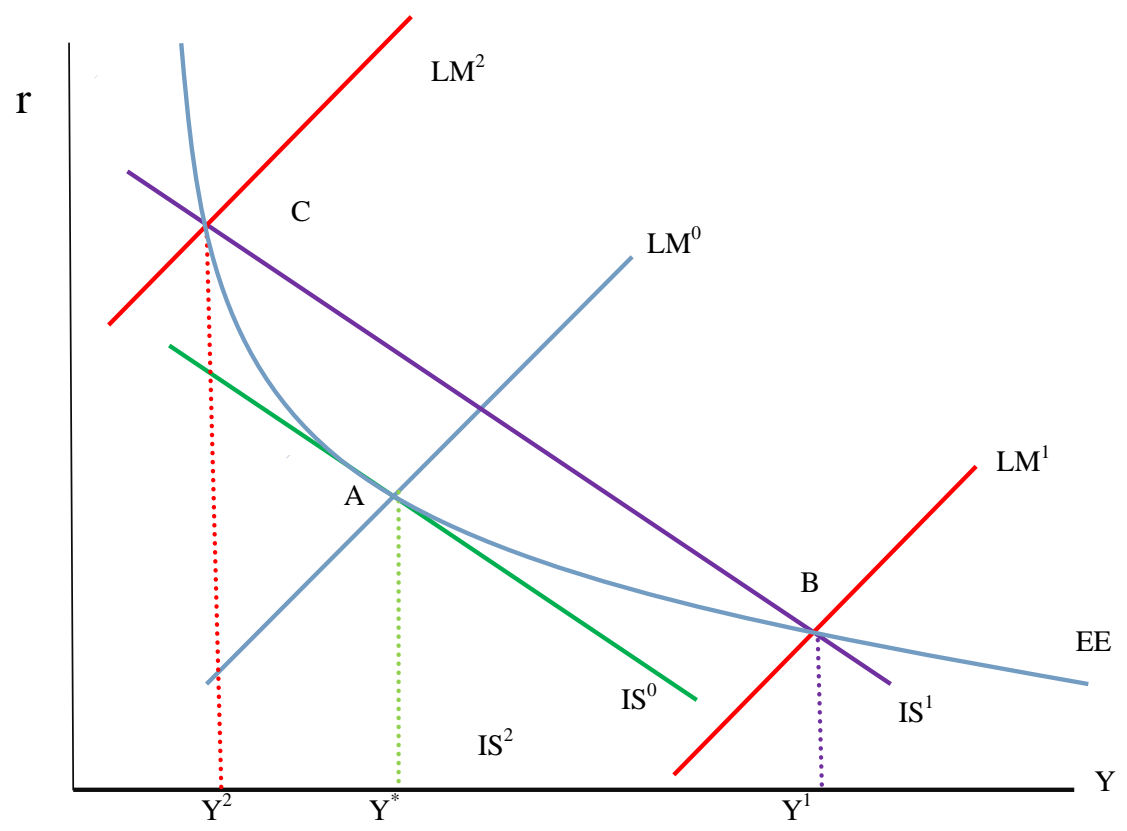

Figure 2. Policy implications in IS-LM-EE Model with EE Schedule of Negative Slope

Then, we discuss the minimium of the government expenditure and of money supply at point $\mathrm{A}$. The minimization problem of government expenditure is: 


$$
\begin{gathered}
\min G=\min _{(Y, r)}\left\{[1-c(1-t)] Y+b r-\left(C_{0}+I_{0}+N X\right)\right\} \\
\text { s.t } \quad\left(e_{0}+\delta r\right) Y=s E
\end{gathered}
$$

So, we will get the solution:

$$
\begin{gathered}
Y^{*}=\left(\frac{b s E}{\delta[1-c(1-t)]}\right)^{\frac{1}{2}} \\
r^{*}=\left(\frac{s[1-c(1-t)] E}{b \delta}\right)^{\frac{1}{2}}-\frac{e_{0}}{\delta} \\
\text { So, } G^{\min }=2\left(\frac{b s E[1-c(1-t)]}{\delta}\right)^{\frac{1}{2}}-\frac{b e_{0}}{\delta}-\left(C_{0}+I_{0}+N X\right)
\end{gathered}
$$

Eq.15 shows the minimium of government expenditure achieving the equilibrium of EE and IS. The government hopes to adjust the money supply to achieve the equilibrium of EE, IS and LM. So the minimium of money supply will be determined by Eq. 2 , Eq.14 and Eq.15, then:

$$
\left(\frac{M_{0}}{P}\right)^{\min }=g\left(\frac{b s E}{\delta[1-c(1-t)]}\right)^{\frac{1}{2}}-h\left(\frac{s[1-c(1-t)] E}{b \delta}\right)^{\frac{1}{2}}+\frac{h e_{0}}{\delta}
$$

The total output, the government expenditure and the money supply of point B are more than point $\mathrm{A}$, which equilibrium point does the government preference between $\mathrm{A}$ and B? It is difficult to answer the problem.

We think that there are two criteria to judge the problem.

a) Risk of expansionary fiscal and tight monetary policy.

The inflation risk is probably induced when the government implements the expansionary monetary policy. The debt risk is probably induced when the government borrows the money to implement the expansionary fiscal policy.

b) Cost and benefit of the implementation of the expansionary fiscal and monetary policy.

The cost and benefit of the policy is weighed when the government implements the expansionary fiscal and monetary policy.

We assume that total output is $Y^{*}$,real interest rate is $r^{*}$, government purchase expenditure is $G^{*}$ and money supply is $\left(\frac{M_{0}}{p}\right)^{*}$ at equilibrium point $\mathrm{A}$, and that total output is $Y_{1}$, real interest rate is $r_{1}$, government purchase expenditure is $G_{1}$ and money supply is $\left(\frac{M_{0}}{p}\right)_{1}$ at equilibrium point B. We define that the cost of fiscal and monetary 
policy is $\Delta G+\Delta\left(\frac{M_{0}}{p}\right)=\left(G_{1}-G^{*}\right)+\left[\left(\frac{M_{0}}{p}\right)_{1}-\left(\frac{M_{0}}{p}\right)^{*}\right]$ and the benefit of fiscal and monetary policy is $\Delta Y=Y_{1}-Y^{*}$ when the government implements the expansionary fiscal and monetary policy from the equilibrium point $\mathrm{A}$ to $\mathrm{B}$.

$$
\Delta G+\Delta\left(\frac{M_{0}}{p}\right)=\Delta Y\left[1-c(1-t)+g+\frac{s E(h-b)}{\delta\left(\Delta Y+Y^{*}\right) Y^{*}}\right]
$$

Therefore,

$$
\begin{aligned}
& \Delta G+\Delta\left(\frac{M_{0}}{p}\right)<\Delta Y \text { when } 1-c(1-t)+g+\frac{s E(h-b)}{\delta\left(\Delta Y+Y^{*}\right) Y^{*}}>1 ; \\
& \Delta G+\Delta\left(\frac{M_{0}}{p}\right)=\Delta Y \text { when } 1-c(1-t)+g+\frac{s E(h-b)}{\delta\left(\Delta Y+Y^{*}\right) Y^{*}}=1 ; \\
& \Delta G+\Delta\left(\frac{M_{0}}{p}\right)>\Delta Y \text { when } 1-c(1-t)+g+\frac{s E(h-b)}{\delta\left(\Delta Y+Y^{*}\right) Y^{*}}<1 .
\end{aligned}
$$

It is feasible for the expansionary fiscal and monetary policy to shift the equilibrium point from A to $\mathrm{B}$ when $\Delta G+\Delta\left(\frac{M_{0}}{p}\right)<\Delta Y$, therefore the government can prefer the equilibrium point $\mathrm{B}$, but the government must weigh the inflation risk of expansionary monetary policy and the debt risk of expansionary fiscal policy. The expansionary fiscal and monetary policy is unfeasible when $\Delta G+\Delta\left(\frac{M_{0}}{p}\right)>\Delta Y$, therefore the government can prefer the equilibrium point $\mathrm{A}$. The cost of the expansionary policy equal to the benefit of the expansionary policy when $\Delta G+\Delta\left(\frac{M_{0}}{p}\right)=\Delta Y$, so the government prefering the equilibrium point $\mathrm{A}$ or $\mathrm{B}$ is indifference,but but the government must weigh the inflation risk of expansionary monetary policy and the debt risk of expansionary fiscal policy at point $\mathrm{B}$.

\section{Conclusion}

Environmental quality has become an important influencing factor to restrict economic development. But environment quality is facing an ordeal owing to the pollution of the soil and water, greenhouse gas, extreme climate and natural disasters. How to maintain better environment quality and to promote economic growth is the focus of attention. In our IS-LM-EE schedule model, we discuss the stability conditions and the policy signification of the equilibrium point. The maximal total output is at the point of tangency of LM and EE schedule when the environmental capital and physical capital is complementary. If the equilibrium point is at the left of the point of tangency, the government will adopt the expansionary fiscal and tight monetary policy to promote the economic growth. The minimal total output is at the point of tangency of IS and EE 
schedule when the environmental capital and physical capital is substitutability. According to the stability condition of the IS-LM-EE model, there are the minimium of the output, of the government expenditure and of the real money supply with the environmental constraint. The cost and benefit of the policy is weighed when the government implements the expansionary fiscal and monetary policy in order to promoting the economic growth.

\section{REFERENCES}

[1] Bernardo, G., Campiglio, E. (2014): A simple model of income, aggregate demand and the process of credit creation by private banks. - Empirica 41(3): 381-405.

[2] Bowen, A., Campiglio, E., Tavoni, M. (2014): A macroeconomic perspective on climate change mitigation: Meeting the financing challenge. - Climate Change Economics 5(1): 1440005.

[3] Campiglio, E. (2016): Beyond carbon pricing: The role of banking and monetary policy in financing the transition to a low-carbon economy. - Ecological Economics 121: 220-230.

[4] Chang, W. W., Smyth, D. J. (1972): Stability and instability of IS-LM Equilibrium. Oxford Economic Papers 24(3): 372-384.

[5] Daly, H. (2013): Nationalize money, not banks. Center for the Advancement of the Steady State Economy. Retrieved from http://steadystate. org.

[6] Daly, H. E. (1991): Elements of environmental macroeconomics. - Ecological economics: The science and management of sustainability, 32-46.

[7] Daly, H. E. (1991): Towards an environmental macroeconomics. - Land Economics 67(2):255-259.

[8] Daly, H. E. (2014): Paul Craig Roberts' important new book. - Ecological Economics 101- 127.

[9] Decker, C. S., Wohar, M. E. (2012): Substitutability or complementarity? Re-visiting Heyes' IS-LM-EE model. - Ecological Economics 74: 3-7.

[10] Douthwaite, R. (2012): Degrowth and the supply of money in an energy-scarce world. Ecological Economics 84: 187-193.

[11] Fontana, G., Sawyer, M. (2016): Towards post-Keynesian ecological macroeconomics. Ecological Economics 121: 186-195.

[12] Halkos, G., Paizanos, E. (2015): Environmental Macroeconomics: A critical literature review and future empirical research directions. https://mpra.ub.unimuenchen.de/67432/1/MPRA_paper_67432.pdf.

[13] Heyes, A. (2000): A proposal for the greening of textbook macro: "IS-LM-EE". Ecological Economics 32(1): 1-7.

[14] Jackson, T., Victor, P. A. (2015): Does credit create a 'growth imperative'? A quasistationary economy with interest-bearing debt. - Ecological Economics 120: 32-48.

[15] Jackson, T., Victor, P. A. (2016): Does slow growth lead to rising inequality? Some theoretical reflections and numerical simulations. - Ecological Economics 121: 206-219.

[16] Lawn, P. A. (2003): On Heyes' IS-LM-EE proposal to establish an environmental macroeconomics. - Environment and Development Economics 8(1): 31-56.

[17] Naqvi, A. (2015): Modeling Growth, Distribution, and the Environment in a Stock-Flow Consistent Framework. - Policy Paper no 18.

[18] Oleck, C. (1961): On the global stability of an autonomous system on the plane. MARTIN CO BALTIMORE MD RESEARCH INST FOR ADVANCED STUDIES.

[19] Rezai, A., Stagl, S. (2016): Ecological Macroeconomics: Introduction and Review. Ecological Economics 121: 181-185. ISSN 0921-8009

[20] Rezai, A., Taylor, L., Mechler, R. (2013): Ecological macroeconomics: An application to climate change. - Ecological Economics 85: 69-76. 
[21] Samuelson, P. A. (1941): The stability of equilibrium: comparative statics and dynamics. - Econometrica: Journal of the Econometric Society 97-120.

[22] Samuelson, P. A. (1942): The stability of equilibrium: linear and nonlinear systems. Econometrica: Journal of the Econometric Society 1-25.

[23] Seyfang, G., Longhurst, N. (2013): Growing green money? Mapping community currencies for sustainable development. - Ecological Economics 86: 65-77.

[24] Sim, N. C. (2006): Environmental Keynesian macroeconomics: some further discussion. Ecological Economics 59(4): 401-405.

[25] Taylor, L., Rezai, A., Foley, D. K. (2016): An integrated approach to climate change, income distribution, employment, and economic growth. - Ecological Economics 121: 196-205.

\section{APPENDIX}

We think that the equilibrium point stability conditions are met in IS-LM-EE model if the equilibrium point stability conditions are met respectively in the IS-LM, IS-EE and LM-EE model at the same time.So we prove the equilibrium point stability conditions of IS-LM-EE model by using the differential system of IS-LM model, the differential algebraic systems of IS-EE and LM-EE model with the given EE schedule.The differential system of IS-LM model, the differential algebraic systems of IS-EE and LM-EE model are as follows:

$$
\begin{gathered}
I S-L M:\left\{\begin{array}{c}
\frac{d Y}{d t}=\alpha\left[c(1-t) Y-Y-b r+\left(C_{0}+I_{0}+N X+G\right)\right] \\
\frac{d r}{d t}=\beta\left(g Y-h r-\frac{M_{0}}{P}\right)
\end{array}\right. \\
I S-E E:\left\{\begin{array}{c}
\frac{d Y}{d t}=\alpha\left[c(1-t) Y-Y-b r+\left(C_{0}+I_{0}+N X+G\right)\right] \\
\left(e_{0}+\delta r\right) Y-s E=0
\end{array}\right. \\
L M-E E:\left\{\begin{array}{c}
\frac{d r}{d t}=\beta\left(g Y-h r-\frac{M_{0}}{P}\right) \\
\left(e_{0}+\delta r\right) Y-s E=0
\end{array}\right.
\end{gathered}
$$

According to Oleck's Theorem (Oleck, 1961) and Routh-Hurwitz Theorem, the local stability conditions of the differential system $A-1$ are if and only if

$$
\begin{gathered}
\text { a) } \alpha[c(1-t)-1]-\beta b<0 \\
\text { b) }-\alpha \beta h[c(1-t)-1]+\alpha \beta g b=\alpha \beta b h\left(k_{L M}-k_{I S}\right)>0
\end{gathered}
$$

The stability condition of the differential algebraic systems $A-2$ and $A-3$ are (Chang and Smyth, 1972): 


$$
\begin{gathered}
{[c(1-t)-1]-\frac{b s E}{\delta Y^{2}}=-b\left(k_{E E}-k_{I S}\right)<0} \\
-h-\frac{g \delta Y^{2}}{s E}=-\frac{h}{k_{E E}}\left[k_{E E}-k_{L M}\right]<0
\end{gathered}
$$

We will obtain the stability of the equilibrium point of the IS-LM-EE model when the formula $(A-4)-(A-7)$ are satisfied at the same time. So the stability of the equilibrium point in IS-LM-EE model is as follows:

a) $\delta>0$ and $k_{L M}>0>k_{E E}>k_{I S}$;

b) $\delta<0$ and $k_{E E}>k_{L M}>0>k_{I S}$. 